\title{
Modeling and analysis of factors affecting seismic pounding of adjacent multi-story buildings
}

\author{
M. Abdel-Mooty ${ }^{1}$, H. Al-Atrpy ${ }^{2} \&$ M. Ghouneim ${ }^{2}$ \\ ${ }^{1}$ Department of Construction and Architectural Engineering, \\ The American University in Cairo, Egypt \\ ${ }^{2}$ Structural Engineering Department, Cairo University, Egypt
}

\begin{abstract}
Pounding or collisions between adjacent buildings occur as a result of building lateral vibrations during strong ground shaking. Pounding creates additional forces and causes damage to buildings, finishing at the point of collision. In this paper, the pounding phenomenon is thoroughly studied where the different factors affecting pounding and its mitigation are investigated. The formulation of pounding equations clearly indicates the nonlinear nature of the problem. Therefore, nonlinear numerical analysis is used for pounding force and displacement calculation. A detailed parametric study is carried out to investigate the effect of various parameters on the structural pounding. Of the many factors influencing the seismic pounding of adjacent buildings, the most important ones are identified and further studied. Among such factors are the earthquake record, the separation distance, the structural system in terms of stiffness and mass distribution, and the building height. One of the variables not thoroughly investigated in previous research and addressed in this paper is the effect of structural damage and cracking on pounding. In total a combination of 144 cases are investigated in this parametric study. Finally, the analysis of the results was carried out where general trends are identified and the effects of the various factors are evaluated.
\end{abstract}

Keywords: pounding, separation distance, seismic gap, nonlinear modeling, parametric study. 


\section{Introduction}

The term "structural pounding" is used to describe collisions between adjacent buildings during earthquakes. This is common when there is insufficient separation distance between the adjacent buildings. The pounding phenomenon has been the main cause for the initiation of collapse in many recorded earthquakes. The severe damage caused by pounding can be noticed easily when strong earthquakes strike metropolitan cities and densely populated urban areas.

Pounding is a very complex phenomenon. It could lead to infill wall damage, plastic deformation, column shear failure, local crushing and possible collapse of the structure. Adjacent structures with different floor levels are more vulnerable when subjected to seismic pounding due to the additional shear forces on the columns causing more damage and instability to the building (Karayannis et al. [1]).

The patterns of the damage vary from minor and architectural damages to major structural damages to even total loss of the building function and its stability. In other words, pounding phenomena in adjacent buildings can be catastrophic and more dangerous than the effect of earthquake on a single building.

Structural pounding was observed in almost all major earthquakes of the last decades (Arnold and Reitherman [2], Anagnostopoulos [3], Anagnostopolos [4]). There are many cases reported where pounding has been identified as a primary cause for the failure. The earthquake of the 1985 in Mexico City is a premiere example of how destructive pounding and structural vibrations are to large structures. The number of building affected by pounding in Mexico City is the largest ever reported from a single earthquake, with almost half of the collapsed structures having symptoms of pounding. Another example is the Loma Prieta earthquake of 1989 that caused severe damage in California where over 200 pounding occurrences involving more than 500 buildings in San Francisco, Oakland, Santa Cruz and Watsonville. Significant Pounding was observed at sites over $90 \mathrm{~km}$ from the epicenter (Maison and Kasai [5]). Many reports from the 1995 Kobe earthquake identified pounding as the major cause of fracture of the bearing supports and potential contributor to the collapse of several bridge decks (Otsuka et al. [6]). The reports of the 1999 Chi-Chi earthquake in Taiwan showed pounding phenomena demonstrated in hammering at expansion joints in some bridges, which caused damage of shear keys and anchor bolts (Earthquake Engineering Research Institute [7]).

\section{Factors affecting pounding}

The complex nature of structural pounding has been the subject of research all around the world. The numerous factors involved in this phenomenon may be a good reason for this complexity. It is, however, important to understand the physical aspects of pounding in order to form a rational basis for methods to mitigate its potentially disastrous consequences. Many papers, research projects, and code provisions listed various factors affecting the pounding phenomena. 
These factors include among others: soil condition, building heights, relative difference between building's heights, separation between adjacent buildings, lateral load resisting structural system, the collision's points location, the peak ground acceleration of the earthquake at the location of building, the fundamental period of the structure, the fill material or expansion joints material (if any), the material of construction (steel, concrete, masonry), story height, type of induced vibrations (in-phase or out-of-phase), damping mechanisms, the adopted methods of pounding mitigation, the location of the structure (standalone or built in a row), the lateral eccentricity and twisting motion (if any), etc.

While some of the abovementioned items have trivial impact on the pounding of structures, others are critical and strongly affect the pounding phenomena. The majority of codes are mainly concerned with the separation distance between adjacent building and structural drift (which includes the effect of building height, lateral load resisting system adopted in the studied structures, seismic zone and torsional effects). In this study, four factors are selected for further studies of their effect on structural pounding of adjacent buildings during seismic events. These factors are: building height, separation between adjacent buildings, seismic zones and earthquake record, and the lateral load resisting system

\section{Formulation of the pounding problem}

There are many ways of idealization of the pounding phenomenon between structures. A structure can be modeled and analyzed using a SDOF (SingleDegree-of-Freedom) model if the mass is essentially concentrated at a single point that can move, translate, or rotate only in one direction, or if the system is constrained in such a way as to permit only a single mode of displacement. In general, the mass of a larger building or structure is distributed throughout the structure and can move in many ways. A realistic description of the dynamic response of such systems generally requires the use of a number of independent displacement coordinates. So, the MDOF (Multi-Degree-of-Freedom) will be used to idealize the pounding phenomenon in this paper.

\subsection{Equation of motion}

In the MDOF analysis procedure, the mass of the structure is assumed to be concentrated at the floor levels, which are further assumed to be rigid and displace in the lateral direction only. Thus, the dynamic behavior of this structure, is completely defined by the displacements of the individual story floor $i, \mathrm{u}_{\mathrm{i}}(\mathrm{t}), i=1, n$, where $n$ is the number of the floors.

The equation of motion of a multi-story building reads:

$$
M \ddot{u}+C \dot{u}+K u=P(t)
$$

where $M, C$, and $K$ are $n \times n$ mass, damping and stiffness matrices, $P(t)$ is the $n \times 1$ time dependent force vector, and $\mathrm{u}$ is the $\mathrm{n} \times 1$ displacement vector, and the dots denote differentiation with respect to time $t$. In the practical methods developed 
for the MDOF analysis, individual elements of the damping matrix are not computed based on local damping properties in the vicinity of the associated degrees of freedom. Instead, damping is usually expressed in terms of damping ratios of the critical damping (Chen and Scawthorn [8]).

For the case of seismic excitation where the dynamic forces are generated due to the ground movement at acceleration $\ddot{u}_{g}$, the equation of motion reads:

$$
M \ddot{u}+C \dot{u}+K u=-M \hat{I}_{g}
$$

where the time dependent displacement response vector $u$ in eqn. (2) is measured relative to the support (foundation), and Î defines the direction of the support excitation and consists of ones for those degrees of freedom in the direction of excitation, and zeros otherwise. Note that the effective inertia force acts at every mass point (Chen and Scawthorn [8]).

\subsection{Equation of motion for the pounding problem}

In this section, the pounding equations of MDOF system are introduced. On the contrary to the response for an independently vibrating single structure the pounding force response for pounding between two structures will depend not only on damping ratios but also on masses and in-between gap size.

Equation of motion can be written for the MDOF systems subjected to pounding under earthquake excitation as follows:

$$
M \ddot{u}+C \dot{u}+K u+F_{P}(t)=-M \hat{I}_{g}
$$

where $F_{P}(t)$ is a vector representing the pounding forces at the floors levels. The use of appropriate numerical model of pounding forces $F_{P}(t)$ during collision between structures is essential for the precise determination of the pounding force response. Pounding itself is a complex phenomenon involving many variables as discussed earlier like crushing and plastic deformations at contact points.

Depending on the structural seismic response of the two adjacent buildings, pounding forces generated by collisions are applied and removed during a short interval of time initiating stress waves, which travel away from the region of contact. The process of energy transfer during impact is highly complicated which makes the mathematical analysis of this type of problem difficult. Several models have been used to simulate pounding force during collisions between structures (Abd El-Monem [9]).

\subsection{Solution of equation of motion}

The equation of motion is solved using either analytical or numerical methods. Due to the non-linear nature of pounding phenomenon, the loading pattern and the fact that it is not a closed form formula or infinite series, the numerical solution is adopted. 
Consequently, the solution of the nonlinear equation of motion will be carried out using step-by-step integration method. Among the many methods of timeintegration available for the solution of the nonlinear equation of motion, the Newmark Beta method will be adopted. The software used in this paper is Sap2000 (version 11), which takes into account the nonlinear properties of the gap element used in the modeling of the pounding phenomenon. The properties of the gap element included in the analysis are the stiffness and the open gap (separation distance). The stiffness of the gap element is considered to have negligible effect on the pounding phenomenon and taken as approximately 20 times the stiffness of the stiffer building (Anagnostopoulos and Spiliopoulos [10]). The program permits the input of earthquake records as time history functions, which is necessary to generate accurate and acceptable results.

\section{Detailed parametric study}

There are many variables in the pounding phenomenon but the most important four factors or parameters according to majority of code provisions are: 1) building height, 2) earthquake records, 3) separation between adjacent buildings, and 4) lateral load resisting system

\subsection{Parametric study program}

The configurations selected for studying the abovementioned parameters are outlined in this section. Four groups are formed for the four parameters where 144 combination cases among the four groups are analyzed. The four groups are formed as follows:

A.Lateral load resisting systems (frames, shear walls with the extent of two full bays, and mixed frame with shear wall extending $1 / 2$ bay):

1. Frame hitting frame

2. Mixed system (frame and shear Wall) hitting mixed system

3. Frame hitting shear wall

4. Shear wall hitting shear wall

B. Building height:

1. 8-story building hitting 12 -story building

2. 8-story building hitting 8 -story building

3. 12-story building hitting 12 -story building

C. Separation distance:

1. $5 \mathrm{~mm}$

2. $20 \mathrm{~mm}$

3. $40 \mathrm{~mm}$

D. Earthquake record scaled to $0.15 \mathrm{~g}$ :

1. El Centro Earthquake

2. Petrolia Earthquake

3. S. Monica Earthquake

4. New Hall Earthquake 
This leaves us with 12 groups (4 cases of lateral load systems for 3 building height cases); each group is analyzed for 12 cases (3 separation distance and 4 earthquake records). The results of such analysis are presented in following section. Due to space limitation, sample dimensions and configuration of the considered systems are shown in Figure 1 and Table 1. More details are found in Al-Atrpy [11].

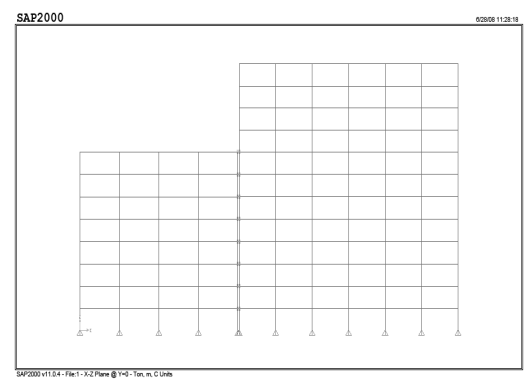

(a) Frame-frame system

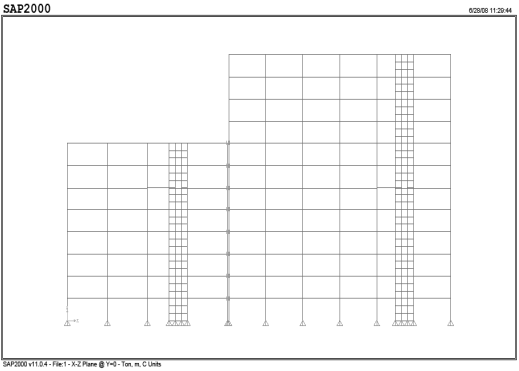

(b) Mixed-mixed system

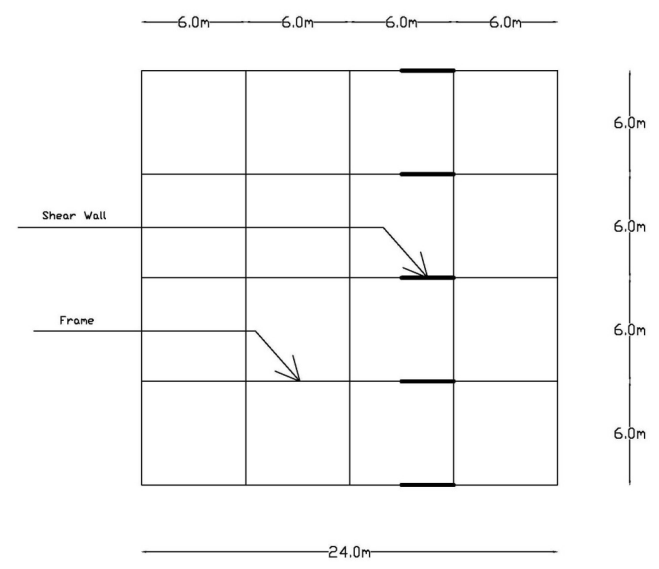

(c) Plan of a mixed frame/shear wall system

Figure 1: $\quad$ Pounding between 8- and 12-story building models.

Table 1: Typical dimensions of structural elements in a 12-story mixed system.

\begin{tabular}{|c|c|c|c|c|}
\hline Floor & $\begin{array}{c}\text { Exterior Column } \\
(\mathrm{mm})\end{array}$ & $\begin{array}{c}\text { Interior column } \\
(\mathrm{mm})\end{array}$ & Beam $(\mathrm{mm})$ & $\begin{array}{c}\text { Shear wall } \\
(\mathrm{mm})\end{array}$ \\
\hline $\mathrm{G} \& 1$ st & $400 \times 1100$ & $400 \times 1200$ & $300 \times 900$ & $300 \times 3000$ \\
\hline $2^{\text {nd }} \& 3^{\text {rd }}$ & $400 \times 1000$ & $400 \times 1100$ & $300 \times 900$ & $300 \times 3000$ \\
\hline $4^{\text {th }} \& 5^{\text {th }}$ & $400 \times 900$ & $400 \times 1000$ & $300 \times 900$ & $300 \times 3000$ \\
\hline $6^{\text {th }} \& 7^{\text {th }}$ & $400 \times 800$ & $400 \times 900$ & $300 \times 900$ & $300 \times 3000$ \\
\hline $8^{\text {th }} \& 9^{\text {th }}$ & $400 \times 700$ & $400 \times 800$ & $300 \times 900$ & $300 \times 3000$ \\
\hline $10^{\text {th }} \& 11^{\text {th }}$ & $400 \times 600$ & $400 \times 900$ & $300 \times 900$ & $300 \times 3000$ \\
\hline
\end{tabular}




\subsection{Analysis of results of the parametric study}

Figure 2-7 shows the effect of building height, structural system, earthquake record and the separation distance on the pounding forces for the considered cases. Figure 3 shows the variation of pounding forces along the building height for 8-story frame hitting 12-story frame system with $5 \mathrm{~mm}$ separation and subjected to Petrolia Earthquake.

The figures show that the pounding forces are very much affected by the characteristic of the earthquake and dynamic characteristics of the building. For some earthquake records large pounding force may be produced for smaller gaps. There is no general trend relating the pounding force to the gap. However as the separation distance increases the number of pounding hits decreases.

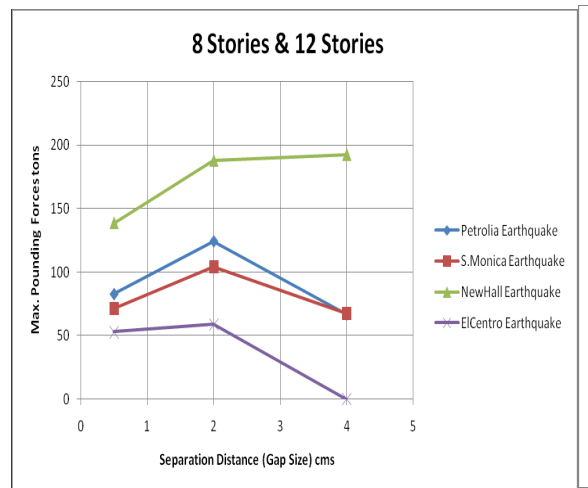

(a) Maximum Pounding Force

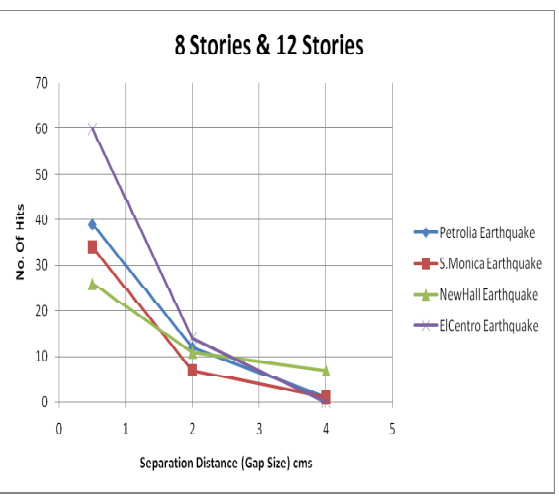

(b) Number of pounding hits

Figure 2: $\quad$ Effect of separation distance and earthquake record on pounding for 8-story frame with 12-story frame system.

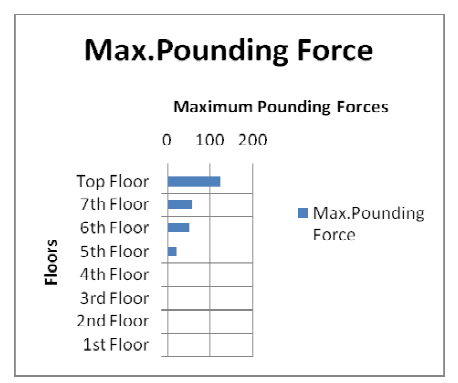

(a) Maximum Pounding Force $(\mathrm{kN})$

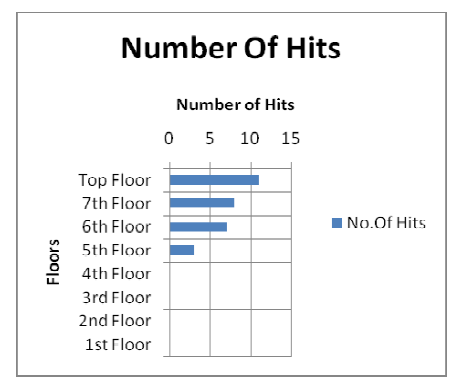

(b) Number of pounding hits

Figure 3: Distribution of pounding forces along the building height for 8story frame with 12 -story frame system. 


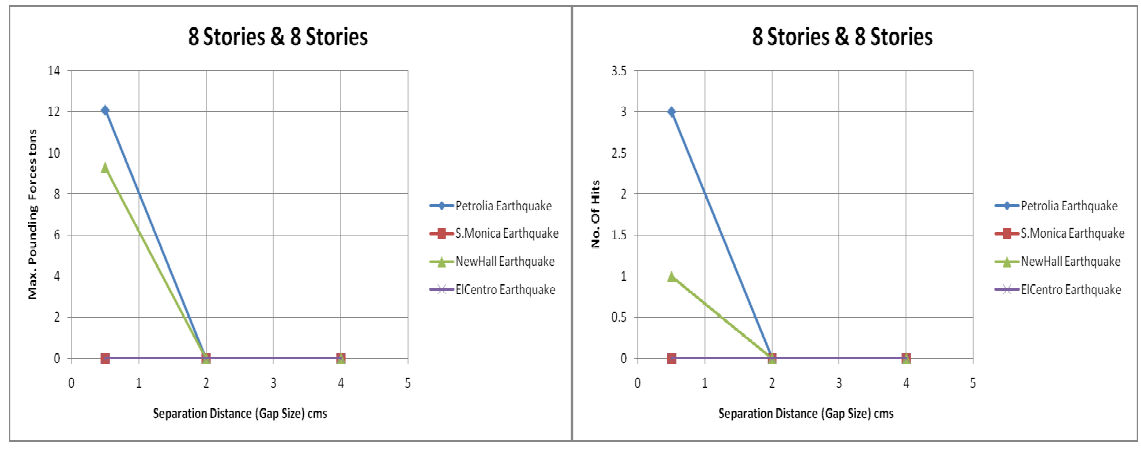

a) Maximum Pounding Force

b) Number of pounding hits

Figure 4: $\quad$ Effect of separation distance and earthquake record on pounding for 8-story frame with 8-story frame system.

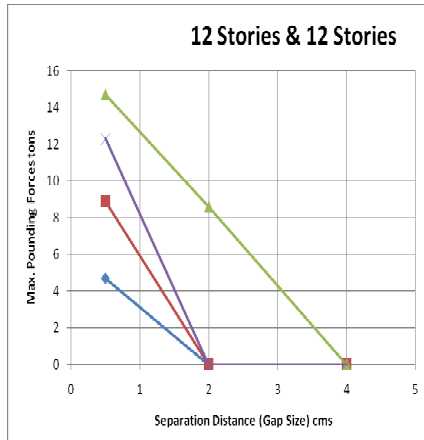

a) Maximum Pounding Force

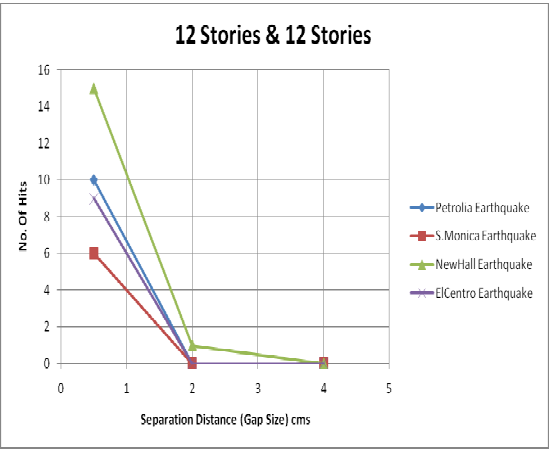

b) Number of pounding hits

Figure 5: $\quad$ Effect of separation distance and earthquake record on pounding for 12-story frame with 12-story frame system.

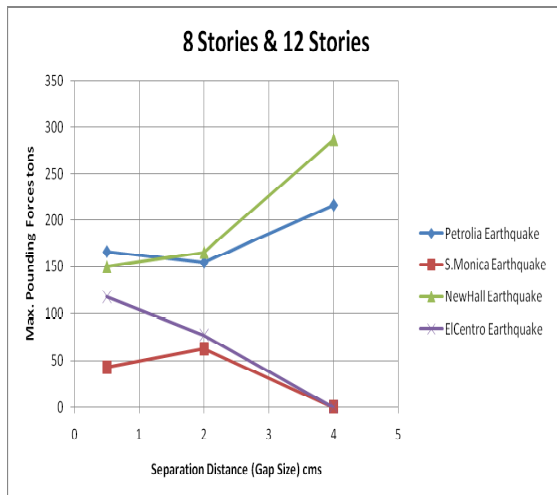

a) Maximum Pounding Force

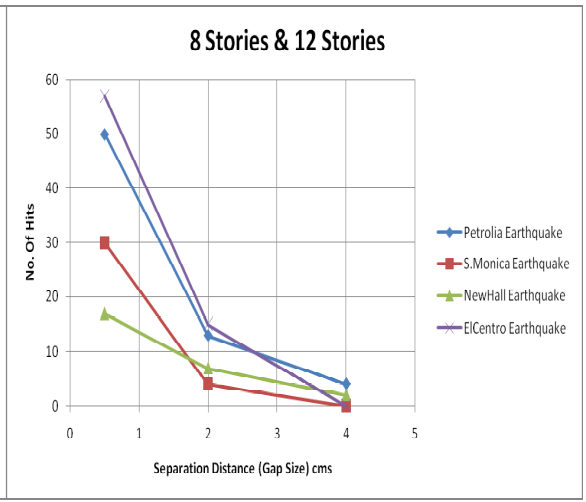

b) Number of pounding hits

Figure 6: $\quad$ Effect of separation distance and earthquake record on pounding for 8-story mixed system with 12-story mixed system. 


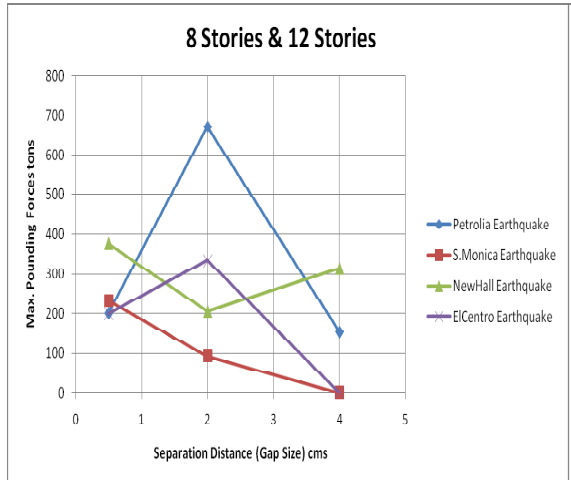

a) Maximum Pounding Force

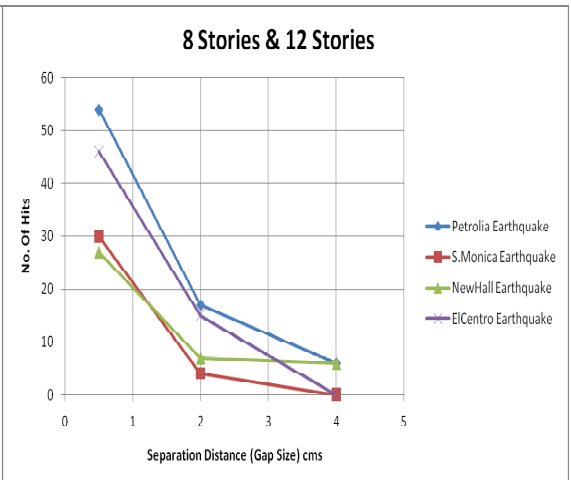

b) Number of pounding hits

Figure 7: Effect of separation distance and earthquake record on pounding for an 8 -story frame system with a 12-story shear wall system.

Table 2: $\quad$ Pounding variation with height for frame-frame system and $20 \mathrm{~mm}$ gap.

\begin{tabular}{|c|c|c|c|c|c|c|}
\hline Story & \multicolumn{2}{|c|}{ 8-stories / 8-stories } & \multicolumn{2}{c|}{ 8-stories / 12-stories } & \multicolumn{2}{c|}{ 12-stories / 12-stories } \\
\hline & Force kN & No. of hits & Force kN & No. of hits & Force kN & No of hits \\
\hline $12^{\text {th }}$ & & & & & 4.7 & 11 \\
\hline $11^{\text {th }}$ & & & & & 3.6 & 10 \\
\hline $10^{\text {th }}$ & & & & & 0 & 3 \\
\hline $9^{\text {th }}$ & & & & & 0 & 0 \\
\hline $8^{\text {th }}$ & 0 & 0 & 124.1 & 5.5 & 0 & 0 \\
\hline $7^{\text {th }}$ & 0 & 0 & 58.5 & 8 & 0 & 0 \\
\hline $6^{\text {th }}$ & 0 & 0 & 51.4 & 7 & 0 & 0 \\
\hline $5^{\text {th }}$ & 0 & 0 & 21.9 & 3 & 0 & 0 \\
\hline $4^{\text {th }}$ & 0 & 0 & 0 & 0 & 0 & 0 \\
\hline $3^{\text {rd }}$ & 0 & 0 & 0 & 0 & 0 & 0 \\
\hline $2^{\text {nd }}$ & 0 & 0 & 0 & 0 & 0 & 0 \\
\hline $1^{\text {st }}$ & 0 & 0 & 0 & 0 & 0 \\
\hline
\end{tabular}

Table 3: Pounding variation with height for mixed-mixed system and 20 mm gap.

\begin{tabular}{|c|c|c|c|c|c|c|}
\hline Story & \multicolumn{2}{|c|}{8 -stories / 8-stories } & \multicolumn{2}{|c|}{ 8-stories / 12-stories } & \multicolumn{2}{c|}{ 12-stories / 12-stories } \\
\hline & Force kN & No. of hits & Force kN & No. of hits & Force kN & No. of hits \\
\hline $12^{\text {th }}$ & & & & & 5.5 & 2 \\
\hline $11^{\text {th }}$ & & & & & 3.8 & 2 \\
\hline $10^{\text {th }}$ & & & & & 0 & 0 \\
\hline $9^{\text {th }}$ & & & & & 0 & 0 \\
\hline $8^{\text {th }}$ & 5.5 & 2 & 155.2 & 13 & 0 & 0 \\
\hline $7^{\text {th }}$ & 24.2 & 2 & 91.5 & 9 & 0 & 0 \\
\hline $6^{\text {th }}$ & 8.5 & 1 & 87.7 & 1 & 0 & 0 \\
\hline $5^{\text {th }}$ & 2.5 & 1 & 0 & 0 & 0 & 0 \\
\hline $4^{\text {th }}$ & 0 & 0 & 0 & 0 & 0 & 0 \\
\hline $3^{\text {rd }}$ & 0 & 0 & 0 & 0 & 0 & 0 \\
\hline $2^{\text {nd }}$ & 0 & 0 & 0 & 0 & 0 & 0 \\
\hline $1^{\text {st }}$ & 0 & 0 & 0 & 0 & 0 & 0 \\
\hline
\end{tabular}


Table 4: $\quad$ Pounding variation with height for frame-wall system and $20 \mathrm{~mm}$ gap.

\begin{tabular}{|c|c|c|c|c|c|c|}
\hline Story & \multicolumn{2}{|c|}{8 -stories / 8-stories } & \multicolumn{2}{c|}{ 8-stories / 12-stories } & \multicolumn{2}{c|}{ 12-stories / 12-stories } \\
\hline & Force kN & No. of hits & Force kN & No. of hits & Force kN & No of hits \\
\hline $12^{\text {th }}$ & & & & & 75.8 & 9 \\
\hline $11^{\text {th }}$ & & & & & 59.2 & 8 \\
\hline $10^{\text {th }}$ & & & & & 68.7 & 8 \\
\hline $9^{\text {th }}$ & & & & & 66.6 & 10 \\
\hline $8^{\text {th }}$ & 913.2 & 17 & 671 & 12 & 152.7 & 9 \\
\hline $7^{\text {th }}$ & 239.1 & 22 & 257 & 12 & 142 & 8 \\
\hline $6^{\text {th }}$ & 455.1 & 11 & 227.7 & 10 & 165.9 & 6 \\
\hline $5^{\text {th }}$ & 221.6 & 5 & 136.70 & 4 & 158 & 3 \\
\hline $4^{\text {th }}$ & 415 & 5 & 96.7 & 6 & 0160.4 & 3 \\
\hline $3^{\text {rd }}$ & 36 & 2 & 52.7 & 4 & 0 & 0 \\
\hline $2^{\text {nd }}$ & 0 & 0 & 0 & 0 & 0 & 0 \\
\hline $1^{\text {st }}$ & 0 & 0 & 0 & 0 & 0 & 0 \\
\hline
\end{tabular}

Tables 2-4 show the variation of pounding forces with height for the same seismic gap $(20 \mathrm{~mm})$ and the same earthquake record (Petrolia) for different structural system and building height. It can be seen that as the differences between the adjacent buildings in structural system and height get larger, the pounding effect becomes more pronounced in both the value of the force and the frequency of occurrence.

Table 5: $\quad$ Effect of concrete cracking on pounding forces for different gap values.

\begin{tabular}{|c|c|c|c|}
\cline { 2 - 3 } \multicolumn{1}{c|}{} & \multicolumn{2}{c|}{ Separation distance 5 mm } & \multicolumn{1}{c}{} \\
\hline & Without cracking & With cracking & $\%$ Change \\
\hline Pounding Force kN & 166.8 & 138.8 & $-16.8 \%$ \\
\hline Number of hits & 34 & 34 & Zero \\
\hline
\end{tabular}

\begin{tabular}{|c|c|c|c|}
\cline { 2 - 3 } \multicolumn{1}{c|}{} & \multicolumn{2}{c|}{ Separation distance $20 \mathrm{~mm}$} & \multicolumn{1}{c}{} \\
\hline & Without cracking & With cracking & $\%$ change \\
\hline Pounding Force $\mathrm{kN}$ & 155.2 & 238.1 & $+53.4 \%$ \\
\hline Number of hits & 9 & 9 & Zero \\
\hline
\end{tabular}

\begin{tabular}{|c|c|c|c|}
\cline { 2 - 3 } \multicolumn{1}{c|}{} & \multicolumn{2}{c|}{ Separation Distance $40 \mathrm{~mm}$} & \multicolumn{1}{c}{} \\
\hline & Without cracking & With cracking & $\%$ of Change \\
\hline Pounding Force kN & 216.5 & 76.8 & $-64.5 \%$ \\
\hline Number of hits & 4 & 5 & $+25 \%$ \\
\hline
\end{tabular}

\subsection{The effect of concrete cracking and local damage on pounding}

The concrete cracking and local repairable damage has a significant effect on the displacements and deformations of the structures. As a result, the pounding phenomenon is greatly affected by this factor. This factor was not thoroughly 
considered in previous research. Concrete cracking is considered in this paper through modified effective moment of inertia $\mathrm{I}_{\text {eff }}$ instead of gross moment of inertia $I_{g}$ according to relevant code provisions. Concrete cracking is mainly applied by reducing the stiffness of the building's members by $35 \%$ for beams, $50 \%$ for shear walls, $70 \%$ for columns.

The effect of concrete cracking is considered on the mixed frame-shear-wall lateral load resistant system as one of the most common systems in Egypt. Also, the geometric configuration of the buildings and the choice of 8-story building hitting 12-story building were to include the whiplash effect. The building was subjected the Petrolia Earthquake record. Three separation distances are studied and the results are shown in Table 5.

The effect of concrete cracking on pounding forces is evedent from the Table 5. Concrete cracking results in reduction of building stiffness associated with increase in drift. However, the effect on pounding, as indicated earlier, depends on the dynamic characteristics of the earthquake record and the building system. In some cases concrete cracking leads to significant increse and in others other cases to a decrease in pounding forces.

\section{Summary and conclusions}

In this paper the factors affecting seismic pounding of adjacent buildings were identified and critically examined. The formulation and modeling of pounding phenomenon is introduced. Parametric study on seismic pounding phenomenon is conducted to examine the effects of various factors on seismic pounding. Finally the effect of structural damage and concrete cracking on seismic pounding is illustrated.

Pounding forces can be calculated using commercial software packages like Sap 2000 where nonlinear gap elements between the adjacent building floors are used to calculate pounding forces. The variation in the stiffness of the gap element has negligible effect on the calculated pounding forces. However, the size of the gap significantly affect the calculated forces their frequency of occurrence.

Pounding forces depends very much on the characteristics of the earthquake records and the dynamic characteristics of the adjacent buildings. The Effect of earthquake record is not limited to just the value of force; it affects the frequency of hits also.

Pounding forces increases as the difference in the structural systems in the adjacent buildings increases. The largest pounding forces occur when there is a difference in height of the adjacent buildings due to the whiplash effect. Highest values of pounding forces occur near the top of the building.

In generally pounding forces decreases as the separation distance increases. However, very small separation distance may prevent the build-up of momentum of the moving masses thus reducing the impact forces. However, this depends very much on the characteristics of earthquake record. It is observed that the number of pounding hits consistently decreases as the separation distance increases. 
Pounding forces are significantly affected by concrete cracking which can be modeled using the effective moment of inertia instead of the gross moment of inertia according to the relevant codes.

\section{References}

[1] Karayannis, C.G. and Favvata, M.J., Earthquake-induced interaction between adjacent reinforced concrete structures with non-equal heights. Earthquake Engineering and Structural Dynamics, 34, pp.1-20, 2005.

[2] Arnold, C. and Reitherman R., Building Configuration and Seismic Design. Wiley: New York, 1982.

[3] Anagnostopoulos, S., Earthquake induced pounding: State-of-the-art. Proc. of the $10^{\text {th }}$ European Conference on Earthquake Engineering, Vol. 2, pp. 897-905, 1995

[4] Anagnostopoulos, S., Building pounding re-examined: How serious a problem is it? Proc. of the $11^{\text {th }}$ World Conference on Earthquake Engineering, Acapulco, Mexico, 1996

[5] Maison, B., and Kasai, K., Dynamics of pounding when two buildings collide, Earthquake Engineering and Structural Dynamics, 21, pp. 771$786,1992$.

[6] Otsuka, H., Unjoh, S., Terayama, T., Hoshikuma, J, and Kosa K., Damage to highway bridges by the 1995 Hyogoken Nanbu earthquake and the retrofit of highway bridges in Japan. $3^{\text {rd }}$ U.S.-Japan Workshop on Seismic Retrofit of Bridges, Osaka, Japan, 10-11 December 1996.

[7] Earthquake Engineering Research Institute, 1999 Chi-Chi, Taiwan, Earthquake Reconnaissance Report, Supplement A to vol. 17, April 2001.

[8] Chen, G. and Scawthorn, C., Earthquake Engineering Handbook, CRC Press, USA, 2003.

[9] Abdel El-Monem, A., Dynamic Response of Adjacent Pounding Buildings under Seismic Effect, M.Sc. Thesis, Cairo University, 2007.

[10] Anagnostopoulos, S. and Spiliopoulous, K., An Investigation of earthquake induced pounding between adjacent buildings. Earthquake Engineering and Structural Dynamics, 21, pp. 289-302, 1992.

[11] Al-Atrpy, H., An Investigation of Earthquake Induced Pounding Between Adjacent Buildings, M.Sc. Thesis, Cairo University, 2008. 